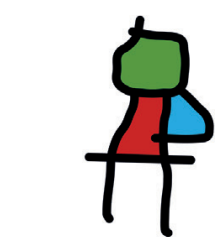

SEICAIP

\section{Allergologia et immunopathologia}

Sociedad Española de Inmunología Clínica, Alergología y Asma Pediátrica

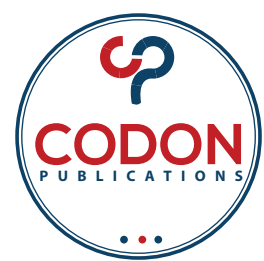

ORIGINAL ARTICLE

\title{
Have asthma symptoms in Mexico changed in the past 15 years? Time trends from the International Study of Asthma and Allergies in Childhood to the Global Asthma Network
}

\author{
Del-Río-Navarro Blanca Estela ${ }^{a}$, Berber Arturob, Reyes-Noriega Nayelya*, \\ Navarrete-Rodríguez Elsy Maureen ${ }^{a}$, García-Almaráz Robertoc, Mérida-Palacio Juan \\ Valente $^{d}$, Ellwood Philippa ${ }^{e}$, García-Marcos Álvarez Luis ${ }^{f}$
}

\author{
a Servicio de Alergia e Inmunología, Hospital Infantil de México Federico Gómez, Mexico City, Mexico \\ ${ }^{b}$ Asesor Externo, Hospital Infantil de México Federico Gómez, Mexico City, Mexico \\ 'Hospital Infantil de Tamaulipas, Ciudad Victoria, Tamaulipas, Mexico \\ ${ }^{d}$ Clínica de asma-alergia Mexicali, Baja California, Mexico \\ 'Department of Paediatrics: Child and Youth Health, University of Auckland, Auckland 1023, New Zealand \\ fPediatric Allergy and Pulmonology Units, 'Virgen de la Arrixaca' University Children's Hospital, University of Murcia, ARADyAL \\ network and Biomedical Research Institute of Murcia (IMIB-Arrixaca), Murcia, Spain
}

Received 12 May 2020; Accepted 7 September 2020

Available online 2 January 2021

\section{KEYWORDS \\ Asthma; \\ GAN; \\ ISAAC; \\ Prevalence; \\ Mexico}

\begin{abstract}
Background: The Global Asthma Network (GAN) builds on the International Study of Asthma and Allergies in Childhood (ISAAC).

Objective: To compare asthma prevalence time trends in primary and secondary school children in four Mexican centers participating in ISAAC and GAN.

Methods: GAN is a cross-sectional, multicenter, epidemiological methodology carried out in groups of primary school children aged 6-7 and adolescents aged 13-14 following the ISAAC Phase Three protocol, with additional questions on risk factors and asthma management.

Results: Overall, the prevalence of asthma symptoms and diagnosis in primary school children was higher in males than in females both in ISAAC $(p<0.05)$ and in GAN $(p<0.01)$, while adolescent females had a higher prevalence, also both in ISAAC $(p<0.001)$ and in GAN $(p<0.001)$. Conclusion: The prevalence of asthma and its symptoms has increased from ISAAC Phase Three since 2003 to GAN Phase I in Mexico in 2019. These findings are in line with the increases observed in the centers with low asthma baseline prevalence in ISAAC Phase One in comparison with ISAAC Phase Three.
\end{abstract}

○ 2021 Codon Publications. Published by Codon Publications.

*Corresponding author: Nayely Reyes Noriega. Hospital Infantil de México Federico Gómez, Dr. Márquez No. 162, Col. Doctores, Deleg. Cuauhtémoc, 06720 México, D.F., Mexico. Email address: naye.rey.nor@gmail.com 


\section{Key messages}

- What is the key question?

- What are the time trends in the prevalence of asthma symptoms in Mexico?

- What is the bottom line?

- The 2003 prevalence of asthma symptoms in Mexico placed the country among the low prevalence countries.

- Why read on?

- The global results show a significant increase in the prevalence of asthma symptoms in Mexico. However, each center has a unique trend pattern.

\section{Introduction}

The International Study of Asthma and Allergies in Childhood (ISAAC) was created in 1991 to increase our current epidemiological understanding of asthma, allergic rhinitis and atopic dermatitis using standard tools and questionnaires in different regions with distinct languages. The ISAAC objectives were to establish the prevalence and severity of allergic diseases; to assess the trends in prevalence and severity of them and to investigate the etiology of these diseases using a standardized methodology. ${ }^{1}$

ISAAC was conducted in three phases. In Phase One (1992-1996), the prevalence and the severity of asthma and other allergic diseases were assessed. Phase Two (19982004) investigated possible etiological asthma factors, and Phase Three (2000-2003) repeated Phase One to establish trends in prevalence. ${ }^{2}$

The comparison of asthma symptoms prevalence between ISAAC Phase One and Phase Three in diverse national centers was reported by Asher et al. ${ }^{3}$ In the primary school children group (6-7 years), 66 study centers had valid reports in both surveys; 25 of them (37.9\%) had increases of one standard error or more, and 14 of them (21.2\%) had decreases of the same magnitude. Meanwhile, in the adolescent group (13-14 years), 106 study centers had valid reports in both surveys; 42 of them (39.6\%) had the respective increases, and 40 of them (37.7\%) had decreases in symptom prevalence. Overall, centers with low prevalence baseline values presented increases in asthma symptoms over time. However, centers with a higher prevalence of asthma symptoms showed frequent decreases across the same period. ${ }^{3}$

In this comparative study, only one Mexican center participated in both ISAAC Phase One and Three (Cuernavaca). The respective 12 month-prevalence of asthma symptoms in primary school children were $8.6 \%$ and $8.4 \%$, respectively, while in adolescents, these were $6.6 \%$ and $11.6 \%{ }^{3}$

The Global Asthma Network (GAN), was founded in 2012 as a successor of ISAAC. GAN Phase I builds on ISAAC's objectives. It uses similar questionnaires and instruments, including the same definitions for "wheezing ever" and "wheezing in the past 12 months", to collect data on prevalence, severity, and diagnosis of asthma, allergic rhinitis and atopic dermatitis, as well as additional questions on emergency room visits, hospital admissions, management, and use of medications related to asthma. ${ }^{4}$

As textually stated by the GAN Steering Group": "The four main hypotheses of GAN Phase I are: (i) globally, the burden of asthma is changing in adults and children; (ii) there is a large variation in the diagnosis of asthma; (iii) in many locations, asthma is under-diagnosed, and its management is suboptimal, and (iv) there are potentially remedial risk factors of asthma." 4

The objective of the present study was to compare, in four Mexican cities, the prevalence of asthma symptoms and diagnosis in ISAAC Phase Three $(2001-2003)^{4}$ versus GAN Phase I surveys (2016-2019).

\section{Participants and methods}

The methodology of ISAAC Phase Three surveys conducted in Mexico has been previously described in the literature, with the same guidelines for the translation of the ISAAC English language questionnaire. The questionnaires translated into Spanish were revised in order to ensure that they had the same structure and logic as the original English version. . $^{, 6}$

The populations of GAN Phase I surveys were primary school children (6-7 years) and adolescents (13-14 years) in North Mexico City; Mexicali (Baja California); Victoria City (Tamaulipas); and urban Toluca (Estado de Mexico).

The survey consisted of the administration of validated, standard questionnaires that were completed by primary school children's parents and by adolescents themselves. Parents or legal guardians of the participants provided written consent. Primary school children gave oral assent and adolescents provided written assent.

GAN Phase I protocol was followed (http://www. globalasthmanetwork.org/surveillance/manual/manual. php; accessed on March 23, 2020). The sample units were schools from each center. They included the entire population of primary school children aged 6-7 years and adolescents aged 13-14 years in those schools. Schools were selected randomly from an alphabetical list of schools in the assigned geographic area of each center. It was necessary to include at least 10 schools (if more than 10 schools were available) to obtain the stipulated sample size of 3000 by age group. Such a sample size was calculated to have enough power to detect significant epidemiological differences in the prevalence and severity of asthma (http:// www.globalasthmanetwork.org/surveillance/manual/manual.php; accessed on March 23, 2020).

\section{Definitions}

Wheezing was defined as a positive answer to the previously validated question: "Have you (has this child) ever had wheezing or whistling in the chest at any time in the past? (WHEZEV)." Current wheezing was defined as a positive answer to the question: "Have you (has this child) had wheezing or whistling in the chest in the past 12 months?" (WHEZ12).

Cumulative prevalence of asthma was defined as a positive answer to question: "Have you (has this child) ever had asthma?” (ASTHMAEV).

These relevant questions about asthma symptoms and diagnosis are presented in Table 1 and Table 2. The questions used to inquire into asthma symptoms were the same 
Table 1 Prevalence of symptoms and diagnosis of asthma in primary school children (6-7 years) in the International Study of Asthma and Allergies in Childhood (ISAAC) vs. the Global Asthma Network (GAN) surveys.

\begin{tabular}{|c|c|c|c|c|c|c|c|}
\hline \multirow[t]{2}{*}{ VARIABLE } & \multirow[t]{2}{*}{ CITY } & \multicolumn{3}{|c|}{ ISAAC } & \multicolumn{3}{|c|}{ GAN } \\
\hline & & SEX & $\mathrm{n} / \mathrm{N}$ & PREVALENCE (CI 95\%) & SEX & $\mathrm{n} / \mathrm{N}$ & PREVALENCE (CI 95\%) \\
\hline WHEEZING & México City & Boys & $350 / 1626$ & $21.5 \%(19.5-23.5)$ & Boys & $337 / 1113$ & $30.3 \%(27.6-33.0)$ \\
\hline \multirow[t]{14}{*}{ EVER } & \multirow[t]{2}{*}{ North area } & Girls & $266 / 1579$ & $16.8 \%(15.0-18.7)$ & Girls & $345 / 1354$ & $25.5 \%(23.2-27.8)$ \\
\hline & & Total & $616 / 3205$ & $19.2 \%(17.9-20.6)$ & Total & $682 / 2467$ & $27.6 \%(25.9-29.4)$ \\
\hline & \multirow[t]{3}{*}{ Mexicali } & Boys & $377 / 1329$ & $28.4 \%(25.9-30.8)$ & Boys & $270 / 962$ & $28.1 \%(25.2-30.9)$ \\
\hline & & Girls & $316 / 1250$ & $25.3 \%(22.9-27.7)$ & Girls & $268 / 1013$ & $26.5 \%(23.7-29.2)$ \\
\hline & & Total & $693 / 2579$ & $26.9 \%(25.2-28.6)$ & Total & $538 / 1975$ & $27.2 \%(25.3-29.2)$ \\
\hline & \multirow{3}{*}{$\begin{array}{l}\text { Ciudad } \\
\text { Victoria }\end{array}$} & Boys & $235 / 1262$ & $18.6 \%(16.5-20.8)$ & Boys & $400 / 1229$ & $32.5 \%(29.9-35.2)$ \\
\hline & & Girls & $227 / 1341$ & $16.9 \%(14.9-18.9)$ & Girls & $291 / 1160$ & $25.1 \%(22.6-27.6)$ \\
\hline & & Total & $462 / 2603$ & $17.7 \%(16.3-19.2)$ & Total & $691 / 2389$ & $28.9 \%(27.1-30.7)$ \\
\hline & \multirow{3}{*}{$\begin{array}{l}\text { Toluca Urban } \\
\text { area }\end{array}$} & Boys & $266 / 1558$ & $17.1 \%(15.2-18.9)$ & Boys & $265 / 1274$ & $20.8 \%(18.6-23.0)$ \\
\hline & & Girls & $206 / 1677$ & $12.3 \%(10.7-13.9)$ & Girls & $244 / 1373$ & $17.8 \%(15.7-19.8)$ \\
\hline & & Total & $472 / 3235$ & $14.6 \%(13.4-15.8)$ & Total & $509 / 2647$ & $19.2 \%(17.7-20.7)$ \\
\hline & \multirow{3}{*}{ Total } & Boys & $1228 / 5775$ & $21.3 \%(20.2-22.3)$ & Boys & $1272 / 4578$ & $27.8 \%(26.5-29.1)$ \\
\hline & & Girls & $1015 / 5847$ & $17.4 \%(16.4-18.3)$ & Girls & $1148 / 4900$ & $23.4 \%(22.2-24.6)$ \\
\hline & & Total & $2243 / 11622$ & $19.3 \%(18.6-20.0)$ & Total & $2420 / 9478$ & $25.5 \%(24.7-26.4)$ \\
\hline \multirow{15}{*}{$\begin{array}{l}\text { WHEEZING } \\
\text { IN THE } \\
\text { PAST } 12 \\
\text { MONTHS }\end{array}$} & \multirow{3}{*}{$\begin{array}{l}\text { México City } \\
\text { North area }\end{array}$} & Boys & $116 / 1626$ & $7.1 \%(5.9-8.4)$ & Boys & $137 / 1119$ & $12.2 \%(10.3-14.2)$ \\
\hline & & Girls & $101 / 1579$ & $6.4 \%(5.2-7.6)$ & Girls & $129 / 1364$ & $9.5 \%(7.9-11.0)$ \\
\hline & & Total & $217 / 3205$ & $6.8 \%(5.9-7.6)$ & Total & $266 / 2483$ & $10.7 \%(9.5-11.9)$ \\
\hline & \multirow[t]{3}{*}{ Mexicali } & Boys & $127 / 1329$ & $9.6 \%(8.0-11.1)$ & Boys & $148 / 964$ & $15.4 \%(13.1-17.6)$ \\
\hline & & Girls & $100 / 1250$ & $8.0 \%(6.5-9.5)$ & Girls & $132 / 1018$ & $13.0 \%(10.9-15.0)$ \\
\hline & & Total & $227 / 2579$ & $8.8 \%(7.7-9.9)$ & Total & 280/1982 & $14.1 \%(12.6-15.7)$ \\
\hline & Ciudad & Boys & $110 / 1262$ & $8.7 \%(7.2-10.3)$ & Boys & $148 / 1238$ & $12.0 \%(10.1-13.8)$ \\
\hline & \multirow[t]{2}{*}{ Victoria } & Girls & $114 / 1341$ & $8.5 \%(7.0-10.0)$ & Girls & $137 / 1166$ & $11.7 \%(9.9-13.6)$ \\
\hline & & Total & $224 / 2603$ & $8.6 \%(7.5-9.7)$ & Total & $285 / 2404$ & $11.9 \%(10.6-13.1)$ \\
\hline & \multirow{3}{*}{$\begin{array}{l}\text { Toluca Urban } \\
\text { area }\end{array}$} & Boys & $101 / 1558$ & $6.5 \%(5.3-7.7)$ & Boys & $91 / 1282$ & $7.1 \%(5.7-8.5)$ \\
\hline & & Girls & $91 / 1677$ & $5.4 \%(4.3-6.5)$ & Girls & $83 / 1378$ & $6.0 \%(4.8-7.3)$ \\
\hline & & Total & $192 / 3235$ & $5.9 \%(5.1-6.7)$ & Total & $174 / 2660$ & $6.5 \%(5.6-7.5)$ \\
\hline & \multirow[t]{3}{*}{ Total } & Boys & $454 / 5775$ & $7.9 \%(7.2-8.6)$ & Boys & $524 / 4603$ & $11.4 \%(10.5-12.3)$ \\
\hline & & Girls & $406 / 5847$ & $6.9 \%(6.3-7.6)$ & Girls & $481 / 4926$ & $9.8 \%(8.9-10.6)$ \\
\hline & & Total & $860 / 11622$ & $7.4 \%(6.9-7.9)$ & Total & $1005 / 9529$ & $10.5 \%(9.9-11.2)$ \\
\hline ASTHMA & México City & Boys & $90 / 1626$ & $5.5 \%(4.4-6.6)$ & Boys & $66 / 1126$ & $5.9 \%(4.5-7.2)$ \\
\hline \multirow[t]{14}{*}{ EVER } & North area & Girls & $54 / 1579$ & $3.4 \%(2.5-4.3)$ & Girls & $63 / 1374$ & $4.6 \%(3.5-5.7)$ \\
\hline & & Total & $144 / 3205$ & $4.5 \%(3.8-5.2)$ & Total & $129 / 2500$ & $5.2 \%(4.3-6.0)$ \\
\hline & Mexicali & Boys & $119 / 1329$ & $9.0 \%(7.4-10.5)$ & Boys & $79 / 972$ & $8.1 \%(6.4-9.8)$ \\
\hline & & Girls & $81 / 1250$ & $6.5 \%(5.1-7.8)$ & Girls & $71 / 1024$ & $6.9 \%(5.4-8.5)$ \\
\hline & & Total & $200 / 2579$ & $7.8 \%(6.7-8.8)$ & Total & $150 / 1996$ & $7.5 \%(6.4-8.7)$ \\
\hline & Ciudad & Boys & $57 / 1262$ & $4.5 \%(3.4-5.7)$ & Boys & $86 / 1248$ & $6.9 \%(5.5-8.3)$ \\
\hline & Victoria & Girls & $67 / 1341$ & $5.0 \%(3.8-6.2)$ & Girls & $74 / 1177$ & $6.3 \%(4.9-7.7)$ \\
\hline & & Total & $124 / 2603$ & $4.8 \%(3.9-5.6)$ & Total & $160 / 2425$ & $6.6 \%(5.6-7.6)$ \\
\hline & Toluca Urban & Boys & $36 / 1558$ & $2.3 \%(1.6-3.1)$ & Boys & $49 / 1294$ & $3.8 \%(2.7-4.8)$ \\
\hline & area & Girls & $29 / 1677$ & $1.7 \%(1.1-2.4)$ & Girls & $44 / 1387$ & $3.2 \%(2.2-4.1)$ \\
\hline & & Total & $65 / 3235$ & $2.0 \%(1.5-2.5)$ & Total & $93 / 2681$ & $3.5 \%(2.8-4.2)$ \\
\hline & Total & Boys & $302 / 5775$ & $5.2 \%(4.7-5.8)$ & Boys & $280 / 4640$ & $6.0 \%(5.3-6.7)$ \\
\hline & & Girls & $231 / 5847$ & $4.0 \%(3.5-4.5)$ & Girls & $252 / 4962$ & $5.1 \%(4.5-5.7)$ \\
\hline & & Total & $533 / 11622$ & $4.6 \%(4.2-5.0)$ & Total & $532 / 9602$ & $5.5 \%(5.1-6.0)$ \\
\hline DOCTOR & México City & Boys & NA & NA & Boys & $59 / 1116$ & $5.3(4.0-6.6)$ \\
\hline DIAGNOSED & North area & Girls & NA & NA & Girls & $51 / 1358$ & $3.8(2.7-4.8)$ \\
\hline ASTHMA & & Total & NA & NA & Total & $110 / 2474$ & $4.4(3.6-5.3)$ \\
\hline & Mexicali & Boys & NA & NA & Boys & $81 / 962$ & $8.4 \%(6.7-10.2)$ \\
\hline & & Girls & NA & NA & Girls & $63 / 1015$ & $6.2 \%(4.7-7.7)$ \\
\hline & & Total & NA & NA & Total & $144 / 1977$ & $7.3 \%(6.1-8.4)$ \\
\hline & Ciudad & Boys & NA & NA & Boys & $80 / 1230$ & $6.5 \%(5.1-7.9)$ \\
\hline & Victoria & Girls & NA & NA & Girls & $74 / 1161$ & $6.4 \%(5.0-7.8)$ \\
\hline & & Total & NA & NA & Total & $154 / 2391$ & $6.4 \%(5.5-7.4)$ \\
\hline
\end{tabular}


Table 1 (Continued)

\begin{tabular}{|c|c|c|c|c|c|c|c|}
\hline \multirow[t]{2}{*}{ VARIABLE } & \multirow[t]{2}{*}{ CITY } & \multicolumn{3}{|c|}{ ISAAC } & \multicolumn{3}{|c|}{ GAN } \\
\hline & & SEX & $\mathrm{n} / \mathrm{N}$ & PREVALENCE (CI 95\%) & SEX & $\mathrm{n} / \mathrm{N}$ & PREVALENCE (CI 95\%) \\
\hline & Toluca Urban & Boys & NA & NA & Boys & $35 / 1278$ & $2.7 \%(1.8-3.6)$ \\
\hline & area & Girls & NA & NA & Girls & $36 / 1376$ & $2.6 \%(1.8-3.5)$ \\
\hline & & Total & NA & NA & Total & $71 / 2654$ & $2.7 \%(2.1-3.3)$ \\
\hline & Total & Boys & NA & NA & Boys & $255 / 4586$ & $5.6 \%(4.9-6.2)$ \\
\hline & & Girls & NA & NA & Girls & $224 / 4910$ & $4.6 \%(4.0-5.1)$ \\
\hline & & Total & NA & NA & Total & $479 / 9496$ & $5.0 \%(4.6-5.5)$ \\
\hline
\end{tabular}

NA .-Not available

Table 2 Prevalence of symptoms and diagnosis of asthma in adolescents (13-14 years) in the International Study of Asthma and Allergies in Childhood (ISAAC) vs. the Global Asthma Network (GAN) surveys.

\begin{tabular}{|c|c|c|c|c|c|c|c|}
\hline \multirow[t]{2}{*}{ VARIABLE } & \multirow[t]{2}{*}{ CITY } & \multicolumn{3}{|c|}{ ISAAC } & \multicolumn{3}{|c|}{ GAN } \\
\hline & & SEX & $\mathrm{n} / \mathrm{N}$ & PREVALENCE (CI 95\%) & SEX & $\mathrm{n} / \mathrm{N}$ & PREVALENCE (CI 95\%) \\
\hline WHEEZING & México City & Boys & $311 / 2036$ & $15.3 \%(13.7-16.8)$ & Boys & $264 / 1600$ & $16.5 \%(14.7-18.3)$ \\
\hline \multirow[t]{14}{*}{ EVER } & \multirow[t]{2}{*}{ North area } & Girls & $348 / 1855$ & $18.8 \%(17.0-20.5)$ & Girls & $400 / 1768$ & $22.6 \%(20.7-24.6)$ \\
\hline & & Total & $659 / 3891$ & $16.9 \%(15.8-18.1)$ & Total & $664 / 3368$ & $19.7 \%(18.4-21.1)$ \\
\hline & \multirow[t]{3}{*}{ Mexicali } & Boys & $97 / 1410$ & $6.9 \%(5.6-8.2)$ & Boys & $288 / 1179$ & $24.4 \%(22.0-26.9)$ \\
\hline & & Girls & $111 / 1578$ & $7.0 \%(5.8-8.3)$ & Girls & $397 / 1258$ & $31.6 \%(29.0-34.1)$ \\
\hline & & Total & $208 / 2988$ & $7.0 \%(6.0-7.9)$ & Total & $685 / 2437$ & $28.1 \%$ (26.3-29.9) \\
\hline & \multirow{3}{*}{$\begin{array}{l}\text { Ciudad } \\
\text { Victoria }\end{array}$} & Boys & $328 / 1503$ & $21.8 \%(19.7-23.9)$ & Boys & $254 / 1163$ & $21.8 \%(19.5-24.2)$ \\
\hline & & Girls & $412 / 1619$ & $25.4 \%(23.3-27.6)$ & Girls & $325 / 1281$ & $25.4 \%(23.0-27.8)$ \\
\hline & & Total & $740 / 3122$ & $23.7 \%(22.2-25.2)$ & Total & $579 / 2444$ & $23.7 \%(22.0-25.4)$ \\
\hline & \multirow{3}{*}{$\begin{array}{l}\text { Toluca Urban } \\
\text { area }\end{array}$} & Boys & $183 / 1451$ & $12.6 \%(10.9-14.3)$ & Boys & $145 / 1342$ & $10.8 \%(9.1-12.5)$ \\
\hline & & Girls & $218 / 1570$ & $13.9 \%(12.2-15.6)$ & Girls & $144 / 1268$ & $11.4 \%(9.6-13.1)$ \\
\hline & & Total & $401 / 3021$ & $13.3 \%(12.1-14.5)$ & Total & $289 / 2610$ & $11.1 \%(9.9-12.3)$ \\
\hline & \multirow[t]{3}{*}{ Total } & Boys & $919 / 6400$ & $14.4 \%(13.5-15.2)$ & Boys & $951 / 5284$ & $18.0 \%(17.0-19.0)$ \\
\hline & & Girls & $1089 / 6622$ & $16.4 \%(15.6-17.3)$ & Girls & $1266 / 5575$ & $22.7 \%(21.6-23.8)$ \\
\hline & & Total & $2008 / 13022$ & $15.4 \%(14.8-16.0)$ & Total & $2217 / 10859$ & $20.4 \%(19.7-21.2)$ \\
\hline \multirow{15}{*}{$\begin{array}{l}\text { WHEEZING } \\
\text { IN THE } \\
\text { LAST } 12 \\
\text { MONTHS }\end{array}$} & \multirow{3}{*}{$\begin{array}{l}\text { México City } \\
\text { North area }\end{array}$} & Boys & $168 / 2036$ & $8.3 \%(7.1-9.4)$ & Boys & $104 / 1601$ & $6.5 \%(5.3-7.7)$ \\
\hline & & Girls & $217 / 1855$ & $11.7 \%(10.2-13.2)$ & Girls & $196 / 1770$ & $11.1 \%(9.6-12.5)$ \\
\hline & & Total & $385 / 3891$ & $9.9 \%(9.0-10.8)$ & Total & $300 / 3371$ & $8.9 \%(7.9-9.9)$ \\
\hline & \multirow[t]{3}{*}{ Mexicali } & Boys & $66 / 1410$ & $4.7 \%(3.6-5.8)$ & Boys & $144 / 1184$ & $12.2 \%(10.3-14.0)$ \\
\hline & & Girls & $70 / 1578$ & $4.4 \%(3.4-5.5)$ & Girls & $220 / 1264$ & $17.4 \%(15.3-19.5)$ \\
\hline & & Total & $136 / 2988$ & $4.6 \%(3.8-5.3)$ & Total & $364 / 2448$ & $14.9 \%(13.5-16.3)$ \\
\hline & Ciudad & Boys & $195 / 1503$ & $13.0 \%(11.3-14.7)$ & Boys & $138 / 1164$ & $11.9 \%(10.0-13.7)$ \\
\hline & \multirow[t]{2}{*}{ Victoria } & Girls & $256 / 1619$ & $15.8 \%(14.0-17.6)$ & Girls & $191 / 1286$ & $14.9 \%(12.9-16.8)$ \\
\hline & & Total & $451 / 3122$ & $14.4 \%(13.2-15.7)$ & Total & $329 / 2450$ & $13.4 \%(12.1-14.8)$ \\
\hline & \multirow{3}{*}{$\begin{array}{l}\text { Toluca Urban } \\
\text { area }\end{array}$} & Boys & $87 / 1451$ & $6.0 \%(4.8-7.2)$ & Boys & $74 / 1343$ & $5.5 \%(4.3-6.7)$ \\
\hline & & Girls & $113 / 1570$ & $7.2 \%(5.9-8.5)$ & Girls & $76 / 1272$ & $6.0 \%(4.7-7.3)$ \\
\hline & & Total & $200 / 3021$ & $6.6 \%(5.7-7.5)$ & Total & $150 / 2615$ & $5.7 \%(4.8-6.6)$ \\
\hline & \multirow[t]{3}{*}{ Total } & Boys & $516 / 6400$ & $8.1 \%(7.4-8.7)$ & Boys & $460 / 5292$ & $8.7 \%(7.9-9.5)$ \\
\hline & & Girls & $656 / 6622$ & $9.9 \%(9.2-10.6)$ & Girls & $683 / 5592$ & $12.2 \%(11.4-13.1)$ \\
\hline & & Total & $1172 / 13022$ & $9.0 \%(8.5-9.5)$ & Total & $1143 / 10884$ & $10.5 \%(9.9-11.1)$ \\
\hline ASTHMA & México City & Boys & $150 / 2036$ & $7.4 \%(6.2-8.5)$ & Boys & $121 / 1601$ & $7.6 \%(6.3-8.9)$ \\
\hline \multirow[t]{5}{*}{ EVER } & \multirow{2}{*}{ North area } & Girls & $160 / 1855$ & $8.6 \%(7.3-9.9)$ & Girls & $129 / 1772$ & $7.3 \%(6.1-8.5)$ \\
\hline & & Total & $310 / 3891$ & $8.0 \%(7.1-8.8)$ & Total & $250 / 3373$ & $7.4 \%(6.5-8.3)$ \\
\hline & \multirow[t]{3}{*}{ Mexicali } & Boys & $17 / 1410$ & $1.2 \%(0.6-1.8)$ & Boys & $104 / 1200$ & $8.7 \%(7.1-10.3)$ \\
\hline & & Girls & $20 / 1578$ & $1.3 \%(0.7-1.8)$ & Girls & $111 / 1273$ & $8.7 \%(7.2-10.3)$ \\
\hline & & Total & $37 / 2988$ & $1.2 \%(0.8-1.6)$ & Total & $215 / 2473$ & $8.7 \%(7.6-9.8)$ \\
\hline
\end{tabular}


Table 2 (Continued)

\begin{tabular}{|c|c|c|c|c|c|c|c|}
\hline \multirow[t]{2}{*}{ VARIABLE } & \multirow[t]{2}{*}{ CITY } & \multicolumn{3}{|c|}{ ISAAC } & \multicolumn{3}{|c|}{ GAN } \\
\hline & & SEX & $\mathrm{n} / \mathrm{N}$ & PREVALENCE (CI 95\%) & SEX & $\mathrm{n} / \mathrm{N}$ & PREVALENCE (CI 95\%) \\
\hline \multirow{24}{*}{$\begin{array}{l}\text { DOCTOR } \\
\text { DIAGNOSED } \\
\text { ASTHMA }\end{array}$} & \multirow{3}{*}{$\begin{array}{l}\text { Ciudad } \\
\text { Victoria }\end{array}$} & Boys & $75 / 1503$ & $5.0 \%(3.9-6.1)$ & Boys & $105 / 1171$ & $9.0 \%(7.3-10.6)$ \\
\hline & & Girls & $108 / 1619$ & $6.7 \%(5.5-7.9)$ & Girls & 107/1291 & $8.3 \%(6.8-9.8)$ \\
\hline & & Total & $183 / 3122$ & $5.9 \%(5.0-6.7)$ & Total & $212 / 2462$ & $8.6 \%(7.5-9.7)$ \\
\hline & \multirow{3}{*}{$\begin{array}{l}\text { Toluca Urban } \\
\text { area }\end{array}$} & Boys & $81 / 1451$ & $5.6 \%(4.4-6.8)$ & Boys & $74 / 1359$ & $5.4 \%(4.2-6.7)$ \\
\hline & & Girls & $74 / 1570$ & $4.7 \%(3.7-5.8)$ & Girls & $89 / 1282$ & $6.9 \%(5.6-8.3)$ \\
\hline & & Total & $155 / 3021$ & $5.1 \%(4.3-5.9)$ & Total & $163 / 2641$ & $6.2 \%(5.3-7.1)$ \\
\hline & \multirow[t]{3}{*}{ Total } & Boys & $323 / 6400$ & $5.0 \%(4.5-5.6)$ & Boys & $404 / 5331$ & $7.6 \%(6.9-8.3)$ \\
\hline & & Girls & $362 / 6622$ & $5.5 \%(4.9-6.0)$ & Girls & $436 / 5618$ & $7.8 \%(7.1-8.5)$ \\
\hline & & Total & $685 / 13022$ & $5.3 \%(4.9-5.6)$ & Total & $840 / 10949$ & $7.7 \%(7.2-8.2)$ \\
\hline & \multirow{3}{*}{$\begin{array}{l}\text { México City } \\
\text { North area }\end{array}$} & Boys & NA & NA & Boys & $93 / 1601$ & $5.8 \%(4.7-7.0)$ \\
\hline & & Girls & NA & NA & Girls & $93 / 1770$ & $5.3 \%(4.2-6.3)$ \\
\hline & & Total & NA & NA & Total & $186 / 3371$ & $5.5 \%(4.7-6.3)$ \\
\hline & \multirow[t]{3}{*}{ Mexicali } & Boys & NA & NA & Boys & $83 / 1181$ & $7.0 \%(5.6-8.5)$ \\
\hline & & Girls & NA & NA & Girls & $80 / 1258$ & $6.4 \%(5.0-7.7)$ \\
\hline & & Total & NA & NA & Total & $163 / 2439$ & $6.7 \%(5.7-7.7)$ \\
\hline & \multirow{3}{*}{$\begin{array}{l}\text { Ciudad } \\
\text { Victoria }\end{array}$} & Boys & NA & NA & Boys & $84 / 1163$ & 7.2\% (5.7-8.7) \\
\hline & & Girls & NA & NA & Girls & $80 / 1285$ & $6.2 \%(4.9-7.5)$ \\
\hline & & Total & NA & NA & Total & $164 / 2448$ & $6.7 \%(5.7-7.7)$ \\
\hline & \multirow{3}{*}{$\begin{array}{l}\text { Toluca Urban } \\
\text { area }\end{array}$} & Boys & NA & NA & Boys & $49 / 1344$ & $3.6 \%(2.6-4.6)$ \\
\hline & & Girls & NA & NA & Girls & $66 / 1273$ & $5.2 \%(4.0-6.4)$ \\
\hline & & Total & NA & NA & Total & $115 / 2617$ & $4.4 \%(3.6-5.2)$ \\
\hline & \multirow[t]{3}{*}{ Total } & Boys & NA & NA & Boys & $309 / 5289$ & $5.8 \%(5.2-6.5)$ \\
\hline & & Girls & NA & NA & Girls & $319 / 5586$ & $5.7 \%(5.1-6.3)$ \\
\hline & & Total & NA & NA & Total & $628 / 10875$ & $5.8 \%(5.3-6.2)$ \\
\hline
\end{tabular}

NA.- Not available

as those used in ISAAC, except for one additional question referring to asthma diagnosis confirmed by a doctor "Was your (was this child's) asthma confirmed by a doctor?" (ASTHDOC).

The period to complete the questionnaires ranged from 2 to 4 years. The completed questionnaires were captured in an electronic database. Data entry and management were performed with Microsoft Excel 2016 v16.0.6568.2036 (Microsoft Corporation). For quality control, double capture was realized in at least $10 \%$ of the total number of questionnaires in order to comply with less than $1 \%$ of capture errors. Electronic databases were centrally reviewed and approved by the data center at the University of Murcia (Spain), which is responsible for the quality control of the Spanish and Portuguese speaking centers in the GAN study. Each center had to complete a report from the center verifying compliance with the methodological standards established by ISAAC and GAN. The report requested a description of the sampling frame, the school selection method, the number of schools excluded and rejected, the participant selection method and data entry, the record of changes made to the data, the number of primary school children and adolescents who participated and refused, as well as a map of the sampling frame of the study area. ${ }^{7}$

\section{Statistical analysis}

Central tendency measurements (mean, standard deviation [SD] and 95\% confidence interval [95\% Cl]), were obtained for the analysis of the accumulated and current prevalence of asthma symptoms and diagnosis in the school children and adolescents group. To detect those variables most probably related to an increase or decrease $(P \leq 0.05)$ in the risk of symptoms of asthma, $\chi^{2}$ tests for categorical variables (corrected using the Fisher exact test if necessary) were performed. The possible associated factors and their relation to environmental variables were analyzed with a logistic regression analysis based on prevalence-adjusted odds ratios (ORs), using the backward conditional method to obtain models that explained the risk of asthma symptoms. These analyses were performed using SPSS 24.0 software (SPSS Inc. IBM Company) and Primer of Biostatistics Version 7 (McGraw-Hill). 
The present study was approved by the Ethics, Investigation, and Biosafety committee of the "Hospital Infantil de México" (Children's Hospital of Mexico) Federico Gómez, with the protocol number HIM/2016/065.

\section{Results}

In GAN, a total of 11,335 elementary school children and 12,262 adolescents from 198 schools were invited to participate in the survey, in the four study centers. However, only 9,688 school children (48.2\% males and $51.7 \%$ females) and 10,972 adolescents (48.7\% males and $51.3 \%$ females) were included. For the ISAAC study, 11,611 school children (49.4\% males and 50.6\% females), and 13,022 adolescents (49.1\% males and $50.9 \%$ females) were included for the analysis, according to ISAAC Phase Three databases. The response rate for the GAN study was higher than those reported in the ISAAC study $(86.02 \%$ vs. $84.3 \%)$ for primary school children and (88.52\% vs. $85.9 \%)$ for the adolescent group. Despite having obtained a response rate of more than $85 \%$ in both age groups of the four centers, there were difficulties in obtaining the total number of questionnaires contemplated due to the lack of delivery of questionnaires answered by parents and adolescents, as well as the elimination of 46 questionnaires in the group of schoolchildren and eight questionnaires in the group of adolescents for being incomplete in more than $10 \%$ of the questions.

The prevalence of "wheezing ever," "wheezing in the past 12 months" and "asthma ever" in male and female participants by study center are presented in Table 1 (primary school children) and Table 2 (adolescents). The global prevalence in both genders (male and female) are shown in Figures 1 and 2, respectively.

In primary school children, the prevalence of wheezing (cumulative prevalence) increased by $32 \%$; wheezing in the past 12 months (current prevalence) increased by $41 \%$, and asthma prevalence increased by $19 \%$. In the adolescent group, the cumulative prevalence increased by $34 \%$, the current prevalence of asthma symptoms increased by $19 \%$, and the prevalence of asthma increased by $45 \%$, with a $p$-value $<0.05$ in both age groups.

This increase was also noticeable in the comparison by sex, where female adolescents had a $38 \%$ increase in the accumulative prevalence of asthma symptoms and a $23 \%$ increase in the current prevalence of asthma symptoms. However, male school children had a higher prevalence of asthma symptoms in the past 12 months (44\%).

When comparing ISAAC versus GAN asthma prevalence in both genders, it can be noted that primary school children showed statistically significant increments ( $p<0.001)$ in "wheeze ever" in North Mexico City (43\%), Victoria City (63\%), and Urban Toluca (31\%) centers. Regarding "asthma ever," a significant increment was seen in Urban Toluca (75\%). All cities in this study had an increment in the prevalence of "wheeze in the past 12 months," these fluctuations being significant $(p<$ 0.05 ) in North Mexico City (57\%), Victoria City (38\%), and Urban Toluca (10\%; Figure 1). Taking the four study centers together, there were statistically significant increments $(p<0.001)$ between both studies in each of the previously reported prevalence.
In the adolescent group, the panorama of prevalence was diverse. In North Mexico City, there was a significant increase in the prevalence of "wheeze ever" (16\%), but no changes in the other two prevalences. Mexicali had a significant increase in the three prevalences (> 25\%). Victoria City had no changes in "wheeze ever" and "wheeze in the past 12 months." However, there was an increase in "asthma ever" values (45\%). Urban Toluca had a statistically significant decrease in "wheeze ever" prevalence values $(19 \%)$ but no changes in the prevalence of "wheeze in the past 12 months" and asthma (Figure 2). Taking the four study centres together, there were statistically significant increments in the three prevalences $(p<0.001)$ between both studies.

\section{Discussion}

Since the first global ISAAC report, the ISAAC Steering Committee reported that the prevalence of allergic diseases was higher in low-resource countries in comparison to developed ones. Furthermore, the report indicated that an evident variability existed at regional and country level. ${ }^{8}$ In ISAAC Phase Three, centers with previously reported low prevalence showed an increment in current asthma symptoms. Additionally, centers with higher baseline prevalence values had decrements. This was particularly seen in the English-speaking and Western European

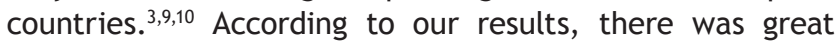
variability in the prevalence of asthma symptoms among the centers studied in Mexico, with a significant increase in Mexicali and Ciudad Victoria located in the northern area of the country. Due to the high variability in the international and inter-city prevalence of asthma, Mallol et al. studied the factors associated with asthma symptoms prevalence in schoolchildren and adolescents with reference to the ISAAC Phase Three results. Those factors were altitude, air pollution as indicated by the predicted concentrations (micrograms per cubic meter) of particles less than $10 \mu \mathrm{m}$ in diameter (PM10) and the Gross National Income (GNI) per capita. According to their report, although there is evidence that air pollution plays an important role in the prevalence of asthma; ISAAC Phase Three found no relationship between air pollution level and current asthma symptoms prevalence. ${ }^{11}$

However, in Mexico, air pollution has been an ecological problem since 2000. Interestingly, in 2017 Mexicali reported an annual concentration of PM10 of $132 \mu \mathrm{g} / \mathrm{m}^{3}$, (the highest pollution levels since 2000, when the mean concentration was $128.5 \mu \mathrm{g} / \mathrm{m} 3$ ) and also reported a significant increase in asthma prevalence in adolescents, taking ISAAC Phase Three as reference. ${ }^{12-14}$ This was followed by Ciudad Victoria with a concentration of PM10 of $108 \mu \mathrm{g} / \mathrm{m}^{3}$ and an increase of $63 \%$ in asthma symptoms prevalence in primary school children. High pollution level trends were also documented in central Mexican cities such as Urban Toluca (PM10 of $74 \mu \mathrm{g} / \mathrm{m}^{3}, 32 \mu \mathrm{g} / \mathrm{m}^{3}$ higher than levels recorded in 2000) and Mexico City $\left(61 \mu \mathrm{g} / \mathrm{m}^{3}, 8 \mu \mathrm{g} / \mathrm{m}^{3}\right.$ higher than 2000).12,14 Notwithstanding, Urban Toluca showed lower asthma prevalence symptoms despite pollution levels. The pollution levels were not the only determinants in the changes in asthma symptoms prevalence. It seems possible 


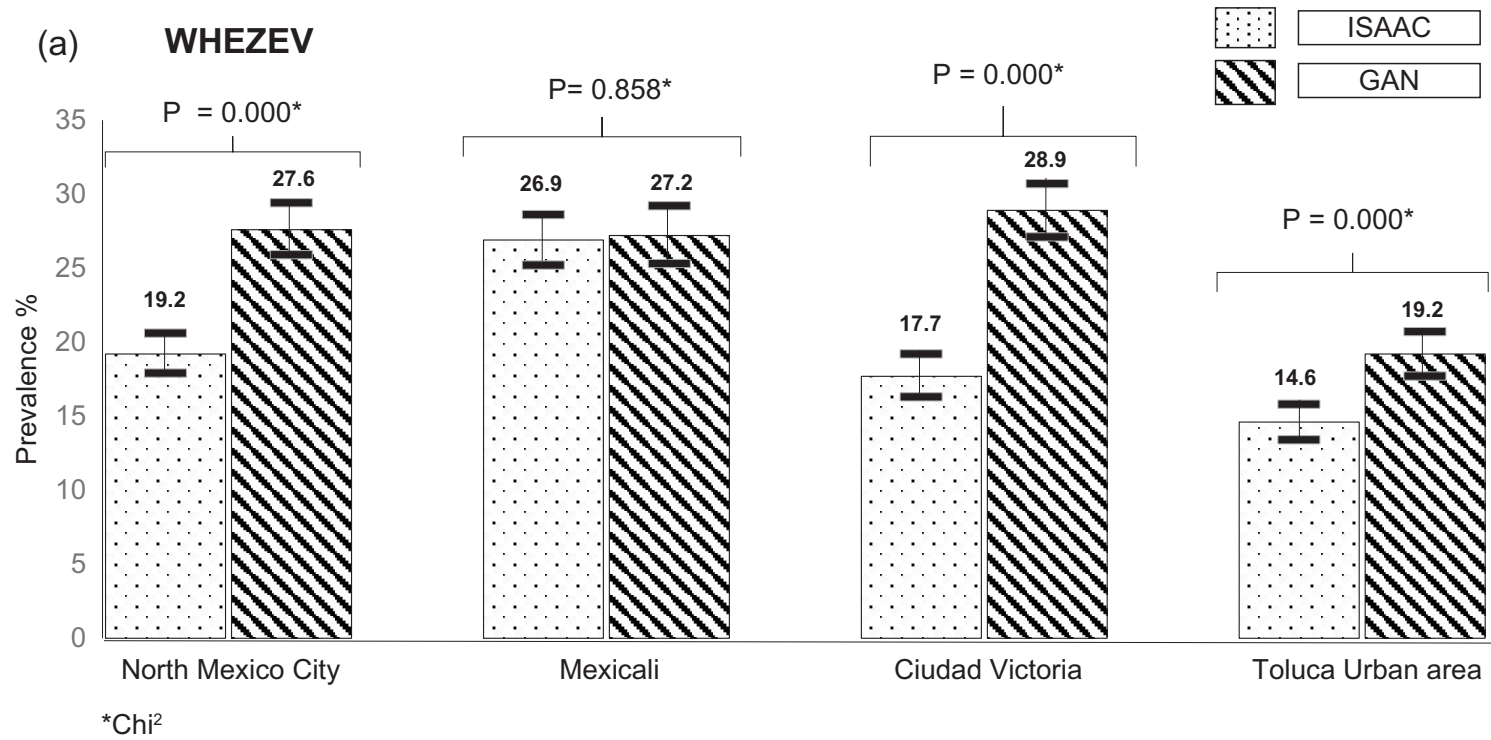

\section{(b) WHEZ12}
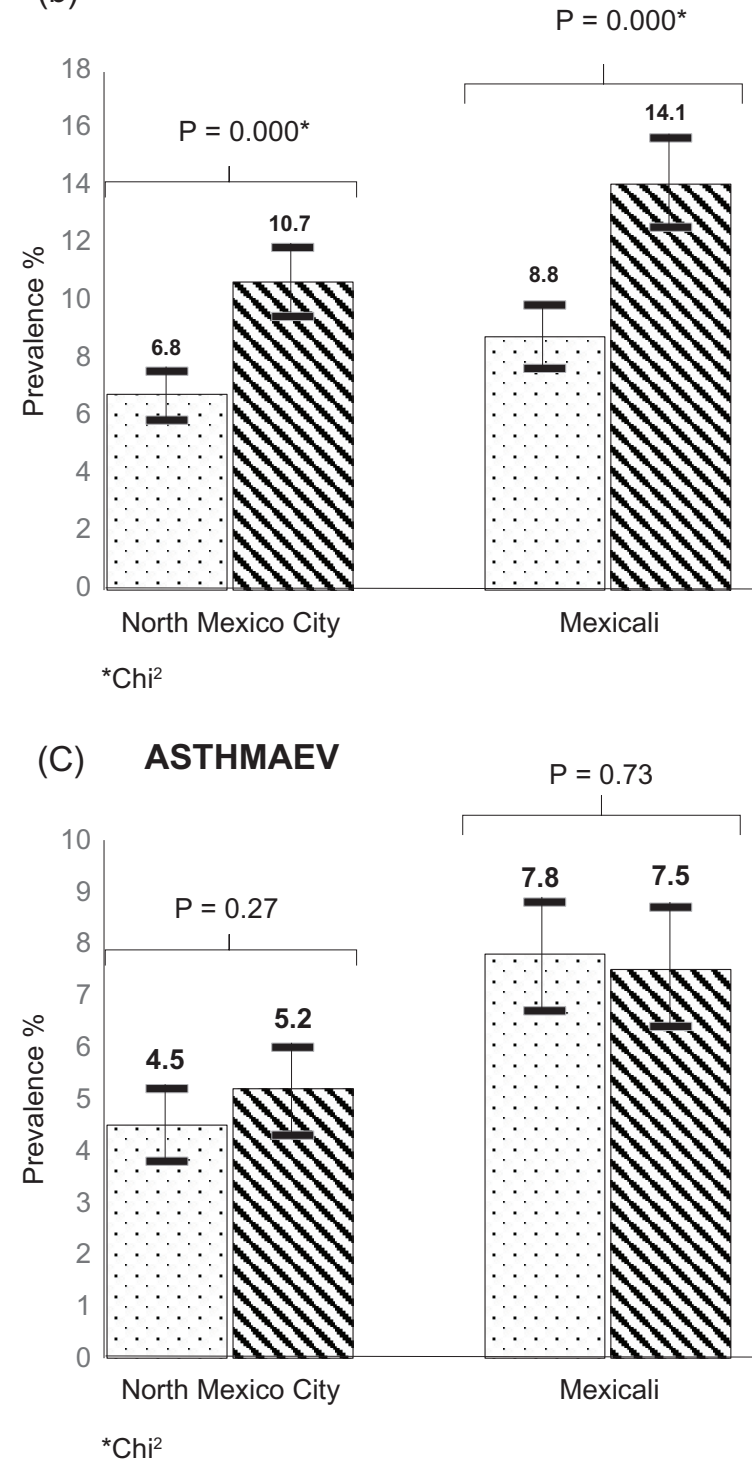

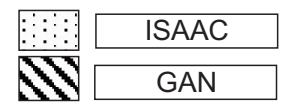

$P=0.000^{*}$

$P=0.397$

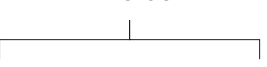


(a) WHEZEV
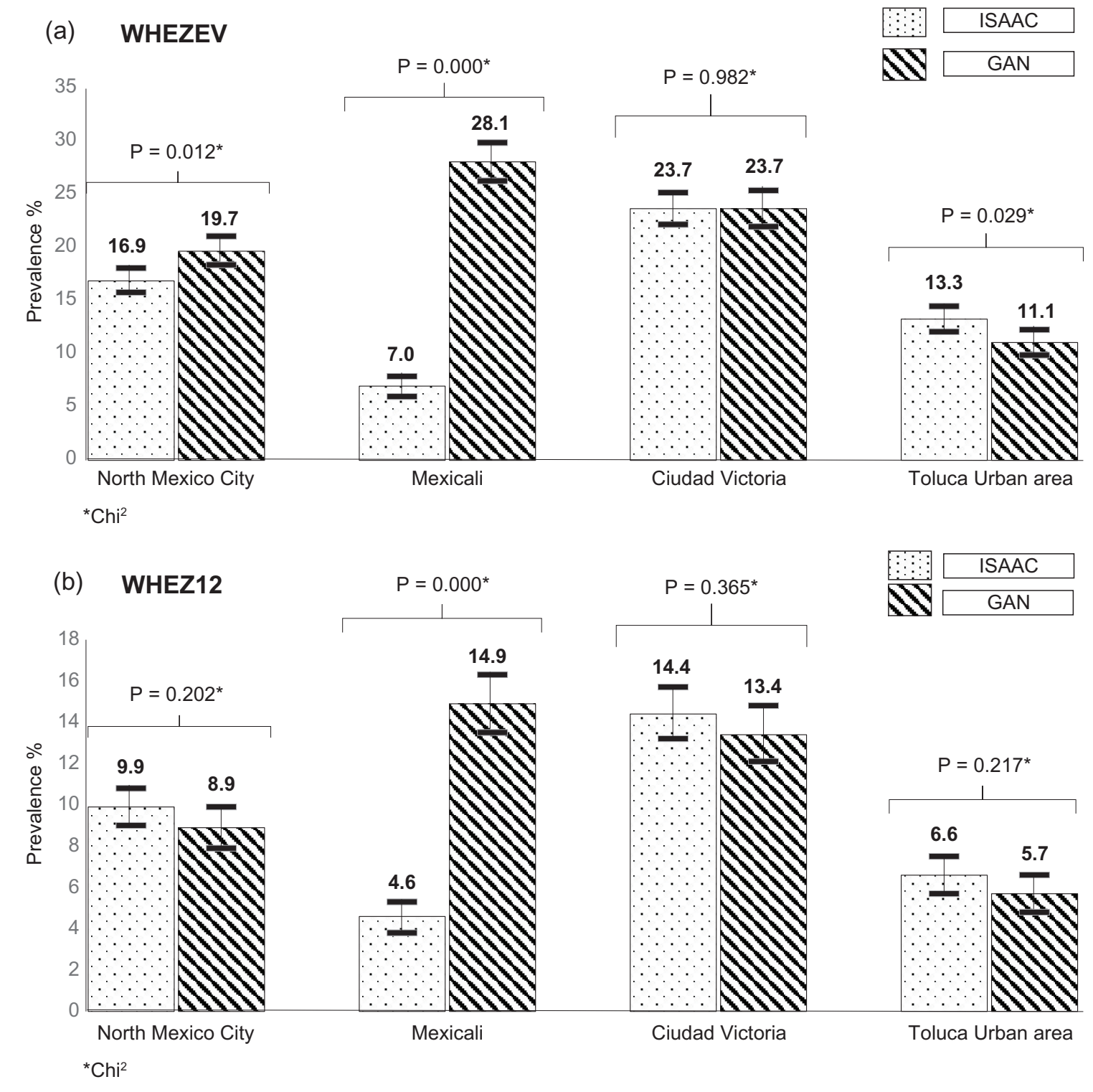
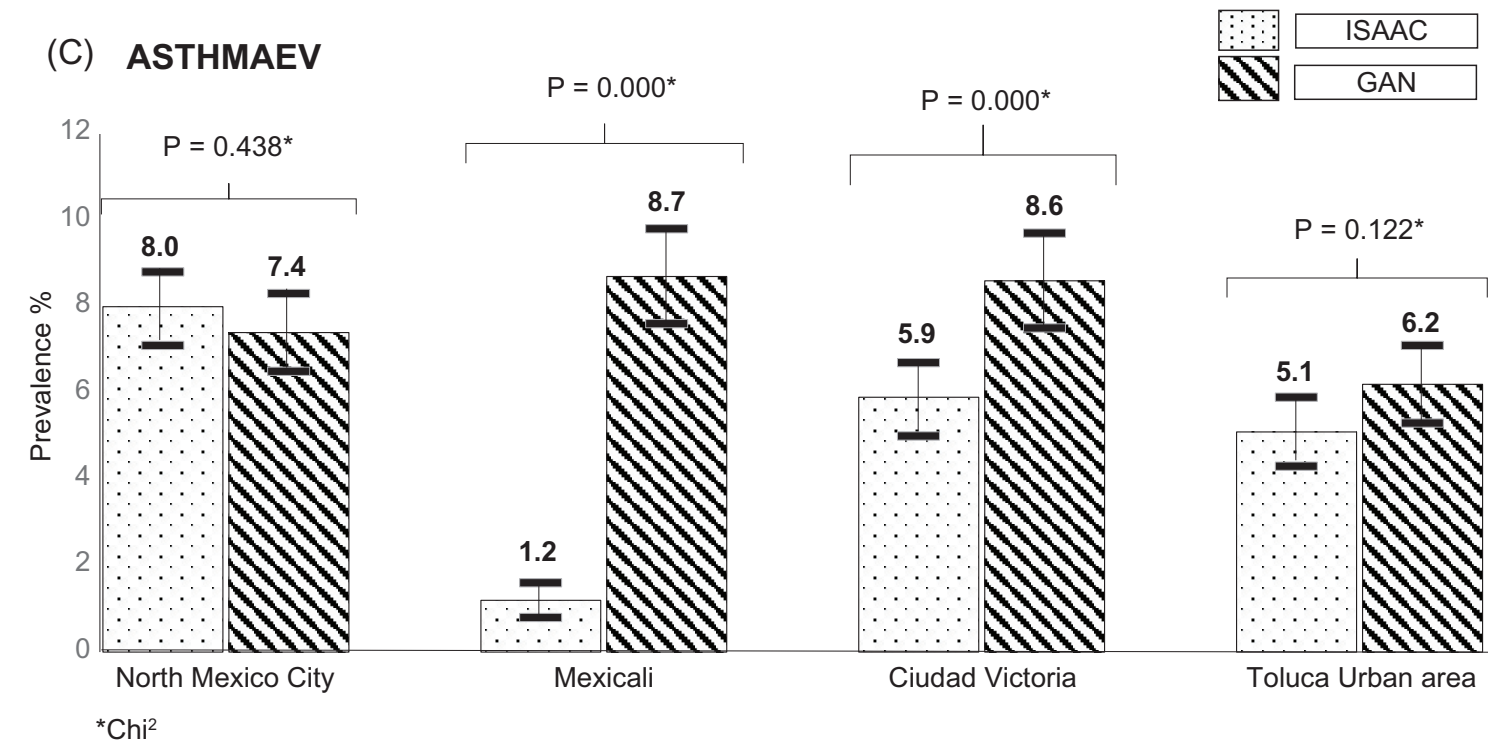

$P=0.000^{*}$

W GAN

Figure 2 (a) Adolescents (13-14 years) prevalence of wheezing ever, (b) wheezing in the past 12 months, and (c) asthma ever in the centers of North Mexico City, Mexicali, Victoria City, and Urban Toluca. Columns represent the punctual prevalence and the bars represent the $95 \%$ confidence intervals. 
that complex ecological interactions in each center could explain the high variability of current asthma in Latin America, such as poverty and poor hygiene, contrary to what is proposed by the "hygiene hypothesis." 15 Studies in Latin America, like that published by Barreto et al., studied the relationship between environmental factors such as sanitation, water supply, electricity, household condition, presence of pets and animals outside the household, contact with animals in farms with asthma symptoms in Brazilian children using ISAAC Phase Three methodology. They reported that lower maternal educational level, lower frequency of routine room cleaning, and household rodent infestation were associated with wheezing in nonatopic children. ${ }^{16}$

Another important social factor related to the symptoms of poverty and asthma was "The Great Recession" during 2007-2009. During the crisis in Mexico, a decrease in net capital inflows and in the industrial area was reported, which mainly affected the Border States with the United States, such as Baja California, Mexicali, Tamaulipas, and Ciudad Victoria. According to national registries, in these states there was a drop of $14.2 \%-17 \%$ in economic activity, leading to a lack of accessibility to health services and medicines. ${ }^{17}$ Another study carried out in the United States evaluated the impact of the economic recession in pediatric patients with asthma, belonging to 50 states. The level of unemployment was selected as an indicator of the economic condition of the population and the purpose was to assess the severity of asthma symptoms in patients aged 2-17 years. In that study, they reported that $69.1 \%$ had symptoms of uncontrolled asthma (25\% had asthma symptoms at night; $57.4 \%$ reported at least one asthma crisis in the last 12 months, and 60\% reported limitation in physical activity due to asthma symptoms). It should be noted that fewer than $50 \%$ of patients with a recent diagnosis of asthma had written medical indications in case of exacerbation of symptoms. That study also reported an increase in parental tobacco smoking, related to anxiety and depression, which also increased the risk of asthma symptoms in primary school children and adolescents. ${ }^{8,18}$ Although this study included some states bordering Mexico, it is possible that the increase in asthma symptoms in primary school children and adolescents in the northern states of Mexico have been related to this economic crisis.

Finally, it is noteworthy that the prevalence of asthma symptoms was higher in male primary school children and this prevalence was reversed in adolescent female participants. Other studies have described gender predisposition in the presentation of asthma as described by Fuseini et al., where males who present dysanapsis during schoolage become predisposed to present asthma symptoms due to the decrease of the bronchoalveolar diameter. ${ }^{10,19}$ Furthermore, exacerbations of asthma symptoms have been reported in females before and during puberty, which tend to worsen during the menstrual cycle. ${ }^{20}$ Experimental studies have reported that the presence of high levels of progesterone and estrogen increase the innate and adaptive immune response responsible for Th2- mediated inflammation of the airways, while 5-alpha dihydrotestosterone $(5 a-D H T)$ does the opposite. ${ }^{19}$

A recent study in adolescents, where the ISAAC methodology was used, reported that females had a higher risk of presenting asthma compared with men and that said risk was consistent in 1994 (OR 1.25; 95\% Cl 1.14-1.36), 2002 (OR 1.61; 95\% Cl 1.19-2.189) and 2015 (OR 1.71; 95\% Cl 1.25-2.33), ( $p<0.001)$. These results also showed that current tobacco use increased in this age group (16.2\% in 1994, $21.8 \%$ in 2002 and $28.9 \%$ in 2015, p < 0.0001) as well as meat consumption between 2002 and 2015 and a significant decrease in consumption of fruit and butter. ${ }^{21}$ Although this tendency was observed in our results, it is important to identify other factors that could contribute to the presence of asthma symptoms in addition to sex, such as the presence of hay fever or eczema symptoms, which increased the risk for asthma symptoms, according to recent reports in Mexico City. ${ }^{22}$

More studies are required to understand the environmental and intrinsic factors that predispose the primary school children and adolescents to develop asthma symptoms, however this study allows us to recognize, with updated information that the prevalence of asthma has been increasing in recent years in four Mexican cities. Taking our results into consideration, further research should explore factors associated with an increase in asthma prevalence in other Mexican states and cities.

\section{Conclusion}

In the present GAN study, we found that the prevalence of asthma symptoms increased significantly in the primary school children and adolescents, taking ISAAC Phase Three results as a reference in Mexico. These findings were in line with increments observed in centers with low baseline asthma prevalence, as demonstrated in the comparison of asthma prevalence between ISAAC Phase One and Three. However, air pollution levels seem to be related to a higher prevalence of symptoms of asthma in primary schoolchildren and adolescents. Further studies on the changes in risk factors and environmental factors are necessary to explain the variability in asthma prevalence increases in Mexican centers.

\section{Limitations}

This multicenter cross-sectional study has limitations typical of an observational study. Apart from questionnaire responses, we did not apply any objective measure or clinical evaluation to confirm asthma symptoms or diagnosis in these populations. On the other hand, self-reporting of symptoms in the adolescent group could lead to higher estimates on the presence of asthma symptoms, and the self-selection centers compared in this study are mainly urban, so it might not be representative of the country.

However, the GAN and ISAAC studies have shown that they are an adequate method to determine the prevalence of symptoms related to allergic diseases, which have increased in the past decade internationally. Although the process of adapting and translating the questionnaire into different languages and socio-cultural contexts has represented a challenge for all the researchers and collaborators involved, a recognizable effort has been made to standardize data management and interpretation, as the guidelines for 
the translation of the ISAAC English language questionnaire to ensure a consistent protocol for countries with different languages, questionnaire translation and back translation into English by an independent person as a key issue for data comparison and a detailed report from each center for verification compliance with the methodological standards established by ISAAC and GAN.6,7 Although this study allows us to know associations and identify potential risk factors, it opens the opportunity to carry out studies that allow analyzing the intrinsic, environmental, and even genetic factors related to the increase in the prevalence of asthma in different areas of the world. It represents an opportunity area to develop the national strategies necessary to detect and care for the population at risk with asthma symptoms.

\section{Acknowledgments}

We thank all the school children, adolescents, and parents who collaborated in the GAN study, for obtaining information and updating the prevalence of asthma. All the authors involved in this article who contributed to the design, elaboration, writing, and analysis of this work. We appreciate the financial support of the Mexican College of Pediatricians Specializing in Allergy and Clinical Immunology (COMPEDIA) to print the questionnaires used for this important project. Likewise, we would like to thank the support of Dr. Innes Asher and her team of collaborators, for their direction in preparing this study, as well as for their support for the inclusion of Mexico in this important international study. Finally, we thank the support of Dra Virginia Pérez Hernández and Axel Arturo Berber del Río, for their contribution to the revision and editing of this article.

\section{References}

1. Asher MI, Keil U, Anderson HR, Beasley R, Crane J, Martinez F, et al. International study of asthma and allergies in childhood (ISAAC): Rationale and methods. Eur Respir J. 1995;8(3):48391. https://doi.org/10.1183/09031936.95.08030483

2. Ellwood P, Asher MI, Beasley R, Clayton TO, Stewart AW. Phase three manual of the international study of asthma and allergies in childhood (ISAAC). August. 2000;2004:10-16.

3. Asher M, Montefort S, Bjorksten B, Lai C, Strachan D, Weiland $S$, et al. Worldwide time trends in the prevalence of symptoms of asthma, allergic rhinoconjunctivitis, and eczema in childhood. Lancet. 2006;368(9537):733-43. https://doi. org/10.1016/S0140-6736(06)69283-0

4. Ellwood P, Asher MI, Billo NE, Bissell K, Chiang CY, Ellwood EM, et al. The global asthma network rationale and methods for Phase I global surveillance: Prevalence, severity, management and risk factors. Eur Respir J. 2017;49(1):1601605. https://doi. org/10.1183/13993003.01605-2016

5. Del-Rio-Navarro B, Berber A, Blandón-Vijil V, RamírezAguilar M, Romieu I, Ramírez- Chanona N, et al. Identification of asthma risk factors in Mexico City in an International Study of Asthma and Allergy in Childhood survey. Allergy Asthma Proceed. 2006;27(4):325-33. https://doi.org/10.2500/ aap.2006.27.2874

6. Ellwood P, Williams H, Aït-Khaled N, Björkstén B, Robertson C, Anderson HR, et al. Translation of questions: The International Study of Asthma and Allergies in Childhood (ISAAC) experience. Int J Tubercul Lung Dis. 2009;13(9):1174-82.
7. Ellwood P, Asher MI, Stewart AW, Ait-Khaled N, Mallol J, Strachan $D$, et al. The challenges of replicating the methodology between Phases I and III of the ISAAC programme. Int J Tubercul Lung Dis. 2012;16(5):687-93. https://doi.org/10.5588/ijtld.11.0226

8. Gonzalez-Barcala FJ, Pertega S, Sampedro M, Lastres JS, Gonzalez MASJ, Bamonde L, et al. Impact of parental smoking on childhood asthma. J Pediatr. 2013;89(3):294-9. https://doi. org/10.1016/j.jped.2012.11.001

9. Kuschner WG. The asthma epidemic. N Engl J Med. 2007;356(10):1073. https://doi.org/10.1056/NEJMc063596

10. Engelkes $M$, Janssens $H M$, de Ridder MAJ, de Jongste JC, Sturkenboom MCJM, Verhamme KMC. Time trends in the incidence, prevalence and age at diagnosis of asthma in children. Pediatr Allergy Immunol. 2015;26(4):367-74. https://doi. org/10.1111/pai.12376

11. Mallol J, Solé D, Baeza-Bacab M, Aguirre-Camposano V, SotoQuiros M, Baena-Cagnani C. Regional variation in asthma symptom prevalence in Latin American children. J Asthma. 2010;47(6):644-50. https://doi.org/10.3109/02770901003686480

12. Instituto Nacional de Ecología y Cambio Climático (INECC). Informe Nacional de Calidad del Aire 2015, México. Coordinación General de Contaminación y Salud Ambiental, Dirección de Investigación sobre la Calidad del Aire y los Contaminantes Climáticos de Vida Corta. Ciudad de México; Diciembre 2016.

13. Reyna Carranza MA. Análisis de la relación del PM10 con las enfermedades respiratorias en la población urbana de Mexicali, Baja California: Un estudio de series de tiempo. Rev Mexicana Ingenier Bioméd. 2003;24(2):116-25.

14. Secretaria del Medio Ambiente y Recursos Naturales. Instituto Nacional de Ecología. https://sinaica.inecc.gob.mx/pags/ informes.php

15. ISAAC Steering Committee. Worldwide variations in the prevalence of asthma symptoms: The International Study of Asthma and Allergies in Childhood (ISAAC). Eur Respir J. 1998;12:31535. https://doi.org/10.1183/09031936.98.12020315

16. Barreto ML, Cunha SS, Fiaccone R, Esquivel R, Amorim LD, Alvim S, et al. Poverty, dirt, infections and non-atopic wheezing in children from a Brazilian urban center. Respir Res. 2010;11:1-10. https://doi.org/10.1186/1465-9921-11-167

17. Díaz Carreño MÁ, Mejía Reyes $P$, Erquizio Espinal $A$, Ramírez Rodríguez R. Recesión los estados México Magnitud causas. Contaduria Administracion. 2015;60:147-68. https://doi. org/10.1016/j.cya.2015.05.005

18. Pearlman DN, Jackson TL, Gjelsvik A, Viner-Brown S, Garro A. The impact of the 2007-2009 US recession on the health of children with asthma: Evidence from the national Child Asthma Call-Back Survey. Med Health Rhode Island. 2012;95(12):394-6.

19. Fuseini $H$, Newcomb DC. Mechanisms driving gender differences in asthma. Curr Allergy Asthma Rep. 2017;17(3):9. https://doi.org/10.1007/s11882-017-0686-1

20. Rao CK, Moore CG, Bleecker E, Busse WW, Calhoun W, Castro $M$, et al. Characteristics of perimenstrual asthma and its relation to asthma severity and control: Data from the Severe Asthma Research Program. Chest. 2013;143(4):984-92. https://doi.org/10.1378/chest.12-0973

21. Mallol J, Aguirre V, Mallol-Simmonds M, MatamalaBezmalinovic A, Calderón-Rodriguez L, Osses-Vergara F. Changes in the prevalence of asthma and related risk factors in adolescents: Three surveys between 1994 and 2015. Allergol Immunopathol. 2019;47(4):313-21. https://doi.org/10.1016/j. aller.2018.10.001

22. Del-Rio-Navarro BE, Navarrete-Rodríguez EM, Berber A, ReyesNoriega N, García-Marcos Álvarez L, García-Almaraz R, et al. The burden of asthma in an inner-city area: A historical review 10 years after Isaac. World Allergy Organ J. 2020;13(1):100092 https://doi.org/10.1016/j.waojou.2019. 